\title{
La Biopelícula : una nueva visión de la placa dental
}

Perez A. La Biopelícula: una nueva visión de la placa dental. Rev Estomatol Herediana 2005;15(1): $82-85$

\section{RESUMEN}

La placa dental es un tipo de biopelícula que se define como una comunidad microbiana diversa que se encuentra en la superficie dental embebida en una matriz de polímeros de origen bacteriano y salival. La formación de la placa involucra la interacción entre las bacterias colonizadoras primarias y la película adquirida del esmalte. Los colonizadores secundarios se unen a las bacterias inicialmente adheridas a través de interacciones moleculares específicas. A medida que la biopelícula se forma, se van desarrollando gradualmente factores biológicos importantes, permitiendo la co-existencia de especies que serían incompatibles si fuera un medio homogéneo. La placa dental se desarrolla naturalmente, pero también está asociada con dos de las enfermedades más prevalentes (caries dental y enfermedad periodontal). Una nueva hipótesis ("hipótesis de la placa ecológica") describe la relación entre las bacterias de la placa y el huésped en la salud y en la enfermedad. Implícito en esta hipótesis se encuentra el concepto de que las enfermedades pueden prevenirse no sólo inhibiendo directamente los patógenos, sino también interfiriendo con los factores ambientales que favorecen la aparición selectiva y crecimiento de estas bacterias. De este modo, podrían establecerse estrategias holísticas para el control y tratamiento de las enfermedades orales.

\section{Palabras clave: PLACA DENTAL / CARIES DENTAL}

\section{Bio-film: A new view of dental plaque \\ ABSTRACT}

Dental plaque is a type of bio-film which is defined as a diverse microbial community found on the tooth surface embedded in a matrix of polymers of bacterial and salivary origin. Plaque formation involves the interaction between early bacterial colonisers and the acquired enamel pellicle. Secondary colonisers adhere to the already attached early bacteria through specific molecular interactions. As the bio-film develops, gradients in biologically significant factors develop, and these permit the co-existence of species that would be incompatible with each other in a homogenous environment. Dental plaque develops naturally, but it is also associated with two of the most prevalent diseases (dental caries and periodontal diseases). A novel hypothesis (the "ecological plaque hypothesis") describes the relationship between plaque bacteria and host in health and in disease. Implicit in this hypothesis is the concept that diseases can be prevented not only by directly inhibiting the putative pathogens, but also by interfering with the environmental factors driving the selection and enrichment of these bacteria. Thus, more holistic strategies could be established for disease control and treatment of oral diseases.

Keywords: DENTAL PLAQUE / DENTAL CARIES

\section{Ada G. Pérez Luyo}

Docente del Departamento Académico de Estomatología del Niño y del Adolescente. Facultad de Estomatología. Universidad Peruana Cayetano Heredia

\section{Correspondencia}

Ada G. Pérez Luyo,

Av. Honorio Delgado 430, Urb. Ingeniería, Lima 31- Perú.

Telf.: 3811950 (anexo 251).

E-mail : adaperezl@metacrawler.com

11105@upch.edu.pe

Aceptado para publicación : 25 de mayo del 2005

\section{Introducción}

La placa dental es un ejemplo claro de una biopelícula y los estudios realizados sobre ella están otorgando una contribución importante para el entendimiento de la etiología y posibilidades de control de la caries dental y la enfermedad periodontal.

Se considera que las biopelículas tienen una fase de crecimiento distinta de las bacterias que se encuentran en estado planctónico, es decir, en suspensión (1). Durante el complejo proceso de adhesión, las células bacterianas alteran sus características fenotípicas como respuesta a la proximidad de una superficie. Durante los estadios iniciales de la formación de la biopelícula, las bacterias sésiles se encuentran en una yuxtaposición estable con células bacterianas de la misma especie y de otras especies, formando de esta mane- ra microcolonias. Esta yuxtaposición celular y la gran producción de matriz de exopolisacáridos, dentro de la biopelícula en desarrollo, condicionan el microambiente de cada biopelícula (1).

Las diferentes bacterias contenidas en la biopelícula responden a las condiciones de sus microambientes específicos, presentando diferentes patrones de crecimiento. La cooperación fisiológica es el factor principal que ayuda a conformar la estructura y establecer la eventual yuxtaposición, haciendo de las biopelículas maduras, adheridas a las superficies, comunidades microbianas muy eficientes (2).

Las enfermedades dentales, que ocurren en sitios donde existe una microflora natural y diversa (placa dental), son el principal problema de salud oral en el mundo, sobre todo en los países en desarrollo. Es por ello, que un mejor enten- dimiento del papel de los microorganismos en el inicio y progresión de las enfermedades dentales es esencial si se quiere reducir su prevalencia.

El conocimiento actual del papel de los microorganismos en la etiología de la caries dental se basa en una nueva hipótesis establecida, la "hipótesis de la placa ecológica” (3). El entendimiento de este nuevo principio permitiría explicar la transición de una microflora oral no patógena hacia una relación patógena con el huésped, así como nuevas oportunidades para el control de la placa dental.

\section{La cavidad oral como hábitat de microorganismos}

Con el fin de identificar los determinantes ecológicos claves que influyen en los patrones de colonización, es necesario comprender las propiedades de 
la cavidad oral. En primer lugar, la boca está continuamente bañada por la saliva, manteniendo una temperatura de 35$36^{\circ} \mathrm{C}$ a un $\mathrm{pH}$ de $6,757,25$, condiciones óptimas para el crecimiento de muchos microorganismos. En segundo lugar, la saliva influye profundamente en la ecología de la boca (4); por ejemplo, su composición iónica promueve sus propiedades de amortiguación y su capacidad para remineralizar el esmalte. Por otro lado, los componentes orgánicos (glicoproteínas y proteínas) pueden a) influir en el establecimiento y selección de la microflora oral, al favorecer la adhesión de ciertos organismos a través de la formación de una película selectiva acondicionadora sobre la superficie del esmalte, o la eliminación de bacterias a través del aclaramiento salival; b) actuar como nutriente endógeno. Así mismo, la saliva contiene componentes de la inmunidad innata y adquirida lo que le da la capacidad de inhibir directamente algunos microorganismos exógenos (4).

\section{Factores ecológicos determinantes de} la composición microbiana.

El papel de las bacterias dentro de una comunidad está dado por las propiedades biológicas de cada población microbiana. Las especies con funciones idénticas en un hábitat compiten por el mismo nicho. La coexistencia de diversas especies en un hábitat se debe a que cada una de ellas tiene una función diferente y se interrelaciona con las otras (5).

La microflora de la placa dental, proveniente de diferentes sitios de la superficie dental, muestra diferencias en su composición. Estas variaciones resultan de las diferencias locales con respecto al suministro de nutrientes, el pH y el potencial redox (6). Tabla 1.

En relación al suministro de nutrientes, éstos comprenden dos categorías : 1) los endógenos, dado por las proteínas y glicoproteínas provenientes de la saliva y del fluido crevicular y 2) los exógenos, dado por los carbohidratos provenientes de la dieta. Los carbohidratos fermentables son los nutrientes que principalmente afectan la ecología microbiana de la cavidad oral. El metabolismo intracelular de los carbohidratos, por parte de las bacterias, lleva a la producción de ácidos que van a acidificar la biopelícula dental (6).

En cuanto al pH, muchas de las especies bacterianas orales crecen en un rango de $\mathrm{pH}$ relativamente limitado. Un ph neutro no tiene impacto sobre los niveles de las especies del grupo mutans, mientras que un $\mathrm{pH}$ bajo lleva a un incremento de estas bacterias (7).

Los organismos anaerobios pueden enfrentarse a los efectos tóxicos del oxígeno interactuando con especies que consumen oxígeno, reduciéndolo a ni-

Tabla 1. Bacterias predominantes presentes en la placa de tres sitios distintos y factores ecológicos determinantes.

\begin{tabular}{llll}
\hline Bacterias & $\begin{array}{l}\text { Fisuras } \\
(\%)\end{array}$ & $\begin{array}{l}\text { Superficie proximal } \\
(\%)\end{array}$ & $\begin{array}{l}\text { Surco gingival } \\
(\%)\end{array}$ \\
\hline Streptococcus & $8-86$ & $<1-70$ & $2-73$ \\
Actinomyces & $0-46$ & $4-81$ & $10-63$ \\
AnG+R* & $0-21$ & $0-6$ & $0-37$ \\
Neisseria & $+* *$ & $0-44$ & $0-2$ \\
Veillonella & $0-44$ & $0-59$ & $0-5$ \\
AnG-R* & ++ & $0-66$ & $8-20$ \\
\hline Medio ambiente & & & FCG \\
\hline Fuente de nutrientes & saliva y dieta & saliva y FCG $+\S$ & neutro-alto \\
pH & neutro-bajo & neutro-bajo & negativo \\
EhCii & positivo & lig. Negativo &
\end{tabular}

*AnG+R, AnG-R: bacterias anaerobias obligadas Gram positivas y bacterias anaerobias Gram negativas, respectivamente.

++ : ocasionalmente detectadas.

$+\S$ FCG: fluido crevicular gingival.

$\mathrm{C}_{\mathrm{ii}}$ Eh: Potencial Redox.

(Tomado de Newman HN, Wilson M, eds. Dental plaque revisited. Oral biofilms in health and disease. UK : BioLine;1999:240) veles que permiten el crecimiento de los primeros (8).

\section{La placa dental: un tipo de biopelícula}

La placa dental se define como una comunidad microbiana que se encuentra sobre la superficie dental, formando una biopelícula embebida en una matriz de polímeros de origen bacteriano y salival. Se presenta en la boca de individuos sanos y enfermos, y es el agente etiológico de dos de las enfermedades orales más prevalentes: la caries dental y la enfermedad periodontal (6).

En 1978, Costerton (9) introdujo el término biofilm. El biofilm, o biopelícula, es una formación de agregados bacterianos, usualmente existentes como comunidades cercanamente asociadas, que se adhieren a una variedad de superficies naturales o artificiales, en un medio acuoso que contiene una concentración suficiente de nutrientes para sostener las necesidades metabólicas de la microbiota.

Se ha determinado que las células bacterianas de la biopelícula exhiben características biológicas que difieren marcadamente de las bacterias que están aisladas, o en suspensión $(9,10)$.

Las biopelículas constituyen una comunidad microbiana protegida de una amplia variedad de factores antibacterianos y que predominan en cualquier ecosistema que posea un nivel suficiente de nutrientes. Todas las biopelículas poseen una estructura y una fisiología complejas, que les permite crear y mantener un ecosistema abierto de canales de agua (6). Un estudio reciente sobre la estructura de la placa dental, demostró que ésta presenta una configuración más abierta de lo que antes se pensaba. Se ha descubierto la presencia de canales que pueden atravesar la profundidad de la biopelícula (11).

\section{Ecología de la placa dental en la salud y enfermedad}

La formación de la placa dental comprende un patrón ordenado de colonización (sucesión microbiana). Los colonizadores primarios pueden retenerse cerca de la superficie dental mediante interacciones físico-químicas no específicas entre las moléculas cargadas provenientes de la célula bacteriana y de la superficie del huésped (12). Posteriormen 
te, se establecen una serie de interacciones intermoleculares específicas bastante fuertes entre las adhesinas bacterianas y los receptores complementarios de la película adherida (acondicionadora), dando como resultado una adherencia irreversible $(13,14)$. Estos colonizadores primarios luego crecen, modificando las condiciones medioambientales locales y haciendo del lugar un medio favorable para la colonización de especies anaerobias. Estos últimos colonizadores se unen a especies bacterianas ya adheridas a través de la co-adhesión $(12,15)$. De esta manera se formarán biopelículas estructuralmente complejas compuestas por diversas especies de microorganismos.

La placa dental, con el tiempo, se convierte en una estructura organizada espacialmente con organismos que ocupan posiciones particulares definidas, debido a las propiedades biológicas y físicas del sitio en el que se encuentran, dando lugar a lo que algunos investigadores han denominado "mosaico de microorganismos" (6).

Una característica clave de una comunidad microbiana es el mantenimiento de una microflora estable en un medio que es variable. Tal estabilidad ha sido denominada "homeostasis microbiana". Esto no significa que no haya actividad metabólica alguna entre las poblaciones microbianas que constituyen la placa. Por el contrario, esta estabilidad es el resultado de un balance dinámico, sostenido por una serie de interacciones, tanto sinérgicas como antagónicas, entre los diferentes grupos microbianos. Estas interacciones incrementan el catabolismo de nutrientes endógenos (proteínas y glicoproteínas) y proveen protección de las presiones del medio, a través del mantenimiento de un medio local favorable aún durante las fluctuaciones desfavorables periódicas que puedan ocurrir en el microambiente. Estas interacciones permiten a los organismos, dentro de una comunidad, persistir y crecer sobre un hábitat más amplio y desplegar acciones sinérgicas en el reciclamiento de nutrientes, incrementando de esta forma la eficiencia metabólica dentro de la comunidad $(6,16)$.

De otro lado, las interacciones antagónicas entre los microorganismos son un factor que contribuyen a determinar la composición de las comunidades microbianas de la placa dental. La producción de compuestos antagónicos, tales como bacteriocinas, o sustancias inhibidoras semejantes a las bacteriocinas, pueden proporcionar a un organismo determinado una ventaja competitiva cuando interacciona con otros (6).

Si bien son numerosos los estudios realizados sobre la asociación entre la composición de la microflora oral y el proceso de la caries dental, la interpretación de los resultados se hace difícil.

Si bien los estudios experimentales en animales han demostrado que la habilidad de inducir caries dental no es una propiedad exclusiva de una especie en particular, han dejado claramente establecido que los estreptococos del grupo mutans (Streptococcus mutans y Streptococcus sobrinus) y los lactobacilos son las bacterias cariógenas más agresivas (17).

van Houte (18) refiere que se ha encontrado estreptococos, que no pertenecen al grupo mutans, con la capacidad de producir ácido y de bajar el nivel de $\mathrm{pH}$, en asociación con algunas lesiones de caries dental en humanos. Este hallazgo indica que otras especies podrían, ocasionalmente, estar involucradas en el proceso de la enfermedad. Estas observaciones apoyan la idea de que si bien, el grupo mutans se encuentra comúnmente en las lesiones inicia-

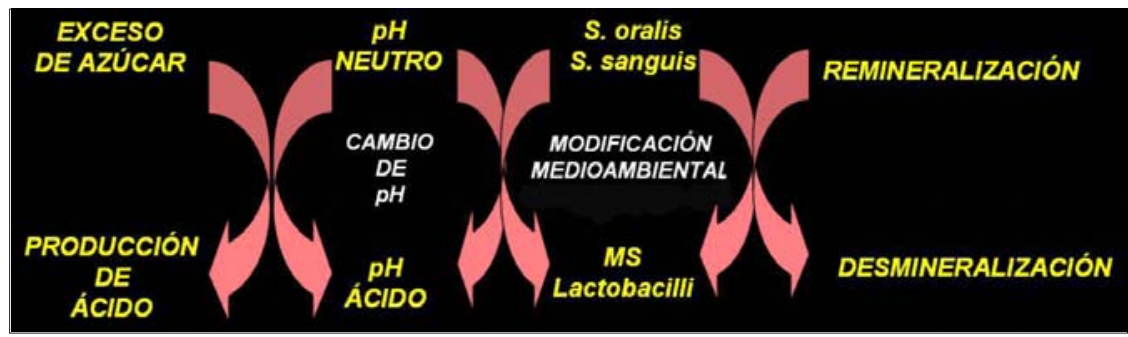

Figura 1. Hipótesis de la placa ecológica de Marsh.

les de caries, no se debería descartar la presencia de otras especies de estreptococos como posibles agentes etiológicos del inicio de la enfermedad.

A lo largo de los años, y con el avance en las investigaciones científicas, las teorías propuestas en relación al papel de la placa bacteriana en el inicio de la caries dental han ido evolucionando.

La hipótesis de la "placa específica”, enunciada por Loesche (19) en 1976, consideraba que, aunque la microflora bacteriana residente en la placa comprenda una variedad de organismos diversos, sólo unas cuantas especies estaban activamente comprometidas con el desarrollo de la enfermedad.

Posteriormente, Theilade (20) en 1986, propuso la hipótesis de la "placa no específica”. Refería que la caries dental era el resultado de la actividad global de la microflora total de la placa. De esta forma, la combinación heterogénea de microorganismos favorecería el desarrollo de la enfermedad.

Recientemente, se concilió los elementos principales de las dos hipótesis anteriores. La hipótesis de la "placa ecológica”, propuesta por Marsh (7) y argumentada por una serie de estudios (21), sostiene que los organismos asociados con la enfermedad pueden estar presentes también en los sitios sanos, pero en niveles tan bajos, que no son clínicamente relevantes. La enfermedad vendría a ser el resultado de los cambios ocurridos en el balance de la microflora que reside en la placa, como consecuencia de la modificación de las condiciones medioambientales locales. Por ejemplo, las condiciones repetidas de un pH bajo en la placa luego del consumo frecuente de azúcares que favorecen el predominio de las especies cariógenas, y la disminución del flujo salival $(7,21)$ (Fig. 1).

En el contexto de la caries dental, puede encontrarse, de manera natural dentro de la placa dental, bacterias potencialmente cariógenas. Sin embargo, en un $\mathrm{pH}$ neutro estos organismos son débilmente competitivos, encontrándose presentes sólo en una proporción muy pequeña. Bajo esta situación y con una dieta no cariógena, los niveles de tales microorganismos potencialmente patógenos son clínicamente insignifi 
cantes, estableciéndose un equilibrio en el proceso de desmineralizaciónremineralización (7). Por el contrario, si se incrementa la frecuencia de ingesta de carbohidratos fermentables, la placa permanecerá más tiempo por debajo del pH crítico para el esmalte ( pH 5,5) lo cual altera la ecología microbiana de la placa. Un pH bajo favorece la proliferación de bacterias acidúricas y acidogénicas, llevando el proceso hacia la desmineralización.

\section{Estrategias fisiológicas para el control de la placa dental}

El concepto de que la caries dental se origina como resultado de las perturbaciones medioambientales del hábitat microbiano, trae como elemento implícito importante que esta enfermedad podría prevenirse no sólo atacando directamente a los patógenos asociados, sino también interfiriendo con los factores responsables de su crecimiento.

En el caso de la caries dental, las condiciones regulares de ingesta de azúcar/pH bajo, parecen ser los mecanismos primarios que rompen la homeostasis microbiana. Las estrategias que son consistentes con la prevención de la enfermedad, según los principios de la hipótesis de la placa ecológica, incluyen (21, 22, 23, 24): (a) inhibición de la producción de ácido (empleo de fluoruros), (b) interferencia en el desarrollo de la biopelícula (empleo de agentes antiplaca como la clorhexidina y el triclosan), (c) evitar la ingesta de azúcares fermentables entre las comidas, (d) consumir alimentos y/o bebidas que contengan azúcares no fermentables (sorbitol, xilitol, aspartame, sacarina) y (e) estimulación del flujo salival después de las comidas principales (empleo de gomas de mascar libres de azúcar).

\section{Conclusiones}

- La placa dental es una biopelícula que posee una alta diversidad de especies bacterianas y presenta una estructura ordenada.

- La caries dental es el resultado de los cambios ocurridos en el balance de la microflora que reside en la placa, como consecuencia de la modificación de las condiciones medioam- bientales locales.

- La reducción del pH, generado por el metabolismo bacteriano de los azúcares, es el factor principal que causa la ruptura de la homeostasis microbiana de la biopelícula.

- La comprensión de la "hipótesis de la placa ecológica” permite reconocer las interrelaciones existentes en la placa dental y por lo tanto la posibilidad de emplear estrategias múltiples para mantener el equilibrio ecológico de esta biopelícula.

\section{Referencias bibliograficas}

1. Costerton JW, Lewandowski Z, Caldwell DE, Korber DR, LappinScott HM. Microbial biofilms. Annu Rev Microbiol 1995;49:711-45.

2. Costerton JW, Lewandowski Z, DeBeer D, Caldwell DE, Korber D, James G. Biofilms, the customized microniche. J Bacterial 1994; 176(8):2137-42.

3. Marsh PD. Sugar, fluoride, $\mathrm{pH}$ and microbial homeostasis in dental plaque. Proc Finn Dent Soc 1991;87:515-25.

4. Scannapieco FA. Saliva-bacterium interaction in oral microbial ecology. Crit Rev Oral Biol Med 1994;5:203-48.

5. Marcantoni M. Ecología de la cavidad bucal. En: Negroni M, ed. Microbiología estomatológica. Fundamentos, guía y práctica. Buenos Aires: Editorial Médica Panamericana;1999:189-94.

6. Marsh PD, Bradshaw DJ. Microbial community aspects of dental plaque. En: Newman HN, Wilson M, eds. Dental plaque revisited. Oral biofilms in health and desease. UK: BioLine;1999:237-53.

7. Marsh PD. Microbial ecology of dental plaque and its significance in health and desease. Adv Dent Res 1994;8(2):263.71.

8. Marquis RE. Oxygen metabolism, oxidative stress and acid-base physiology of dental plaque biofilms. J Int Microbiol 1995;15:198-207.

9. Listgarten MA. Formation of dental plaque and other oral biofilms. En: Newman HN, Wilson M, eds. Dental Plaque revisited. Oral biofilms in health and desease. UK: BioLine;1999:187-210.
10. Rudney JD. Saliva and dental plaque. Adv Den Res 2000;14:29-39.

11. Wood SR, Kirkham J, Marsh PD, Schore RC, Nattress B, Robincson C. Architecture of intact natural human plaque biofilms studied by confocal laser scanning microscopy. J Dent Res 2000;79(1):21-7.

12. Busscher HJ, van der Mei HC. Physico-chemical interactions in inicial microbial adhesión and relevante for biofilm formation. Adv Dent Res 1997;11:24-32.

13. Whittaker CJ, Klier CM, Kolenbrabder PE. Mechanisms of adhesión by oral bacteria. Annu Rev Microbiol 1996;50:513-52.

14. Jenkinson HF, Lamont RJ. Streptococcal adhesion and colonization. Crit Rev Oral Biol Med 1997;8:175-200.

15. Kolenbrander PE, London J. Adhere today, here tomorrow:oral bacteria adherente. J Bacteriol 1993;175:324752.

16. Marshall KC. Biofilms: an overview of bacterial adhesion, activity and control at surfaces. ASM News 1992;58(4):202-8.

17. Marsh PD. Microbiologic aspects of dental plaque and dental caries. Dent Clin North Am 1999;43:599-614.

18. van Houte J. Role of microorganisms in caries etiology. J Dent Res 1994; 73(3):672-81.

19. Loesche WJ. Chemotherapy of dental plaque infections. Oral Sci Res 1976;9:65-107.

20. Theilade E. The non-specific theory in microbial etiology of inflammatory periodontal diseases. J Clin Periodontol 1986;13:905-11.

21. Marsh PD. Are dental diseases examples of ecological catastrophes? SGM Special Lectura. Microbiology 2003; 149:279-94.

22. Marsh PD, Bradshaw DJ. Physiological approaches to the control of oral biofilms. Adv Dent Res 1997;11(1):176-85.

23. Baehni PC, Takeuchi Y. Anti-plaque agents in the prevention of biofilmassociated oral diseases. Oral Diseases 2003;9(Suppl. I):23-9.

24. Hanham A, Addy M. The effect of chewing sugar-free gum on plaque regrowth at smooth and occlusal surfaces. J Clin Periodontol 2001;28:255-7. 